\title{
ANALISIS LAPORAN KEUANGAN DALAM MENILAI KINERJA KEUANGAN PERUSAHAAN PADA BANK PERKREDITAN RAKYAT (BPR) DANA RAYA MANADO
}

\author{
Wilna Feronika Rabuisa ${ }^{1}$, Treesje Runtu ${ }^{2}$, Heince Wokas ${ }^{3}$ \\ ${ }^{1}$ Jurusan Akutansi, Fakultas Ekonomi dan Bisnis, Universitas Sam Ratulangi, Jln. Kampus Bahu, Manado, \\ 95115, Indonesia \\ E-mail : wrambingrabuisa@yahoo.com
}

\begin{abstract}
In the world of banking, finance is very influential on the continuity of the activities of a banking as well as any individual in the banking it. In a company also required an analysis of financial statements to determine the company's ability to overcome the company's financial problems as well as decision making fast and precise. The formulation of the problem in this research is how the financial performance of Rural Banks (BPR) Dana Raya Manado period 2014-2016. The purpose of research is to know the financial performance of Rural Banks (BPR) Dana Raya Manado period 2014-2016. Data analysis technique used in this study by using bank financial ratios. Based on the results of research on the financial ratios of corporate banks are still experiencing fluctuations. Assessment of the Liquidity of Rural Banks Manado Funds Fund is still able to pay its financial obligations. Assessment of Solvency The Bank has adequate capital. Assessment of the company's profitability still has an increased profit.
\end{abstract}

Keywords : Financial Statement, Financial Ratios, Profitabilitas, Rentabilitas

\section{PENDAHULUAN}

\subsection{Latar Belakang Masalah}

Dalam dunia perbankan, keuangan sangat berpengaruh terhadap kelangsungan kegiatan suatu perbankan serta pula pada setiap individu yang ada di dalam perbankan itu tersebut. Dalam suatu perusahaan juga diperlukan analisis terhadap laporan keuangan untuk mengetahui kemampuan perusahaan dalam mengatasi masalah-masalah keuangan perusahaan serta pengambilan keputusan yang cepat dan tepat. Perkembangan posisi keuangan mempunyai arti yang sangat penting bagi perusahaan untuk menilai baik atau tidaknya suatu perusahaan dan tidak hanya dinilai dari keadaan fisik perusahaan namun faktor terpenting yaitu dapat menilai perkembangan suatu perusahaan yang terletak pada unsur keuangannya. Karena unsur tersebut dapat mengevaluasi kebijakan yang ditempuh perusahaan sudah tepat atau tidak.

Analisis laporan keuangan adalah hasil terakhir dari sebuah proses akuntansi yang memberikan gambaran tentang suatu keadaan dari posisi keuangan, hasil usaha, serta perubahan dalam posisi keuangan suatu perusahaan. Laporan keuangan juga merupakan kesimpulan dari pencatatan transaksi yang dilakukan oleh suatu perusahaan. Laporan keuangan sebagai media yang paling penting untuk dapat menilai kondisi ekonomi perusahaan. Laporan keuangan harus ditata dengan didasari oleh Standar Akuntansi Keuangan yang ditetapkan oleh Ikatan Akuntan Indonesia. SAK memberikan fleksibilitas dalam memilih metode yang akan digunakan.

Analisis laporan keuangan menggunakan perhitungan rasio-rasio agar dapat mengevaluasi keadaan finansial perusahaan dimasa lalu, sekarang, dan masa yang akan datang. Rasio-rasio tersebut dapat dihitung dengan didasari sumber datanya yang terdiri tas rasio neraca dari data perusahaan tahun 2014 pada kas dengan jumlah 100,92 pada tahun 
2015 dengan jumlah 289,010 dan pada tahun 2016 sebesar 181,821. Selanjutnya, pada utang perusahaan tahun 2014 mencapai angka 5,683,371 pada tahun 2015 dengan angka 7,094,777 dan pada tahun 2016 mencapai 4,006,648. Pada modal perusahaan tahun 2014 mencapai 5.000.000 pada tahun 2015 dengan angka mencapai 6.000.000 dan pada tahun 2016 dengan angka tetap 6.000.000.

Dengan jumlah rasio-rasio laporan laba-rugi yang disusun dari data yang berasal dari perhitungan laba-rugi, dan rasio-rasio antar laporan yang disusun berasal dari data neraca dan laporan laba-rugi. Laporan keuangan harus disusun agar dapat mengetahui apakah kinerja perusahaan tersebut akan meningkat atau bahkan menurun.

\section{TINJAUAN PUSTAKA}

\subsection{Konsep Akuntansi}

\subsubsection{Pengertian Akuntansi}

Menurut Pura (2013 : 4 ) pengertian akuntansi yaitu seperangkat atas pengetahuan yang mempelajari perekayasaan dalam penyediaan jasa,berupa informasi keuangan kuantitatif dari suatu organisasi dan cara penyampaian informasi tersebut kepada pihak yang berkepentingan untuk dijadikan sebagai tolak ukur dalam pengambilan keputusan ekonomi.

\subsubsection{Tujuan Akuntansi}

Beberapa tujuan dari akuntansi menurut Pura (2013) sebagai :

a. Sebagai tolak ukur terhadap informasi yang dipercayai kebenarannya mengenai kewajiban, modal, dan sumber ekonomi.

b. Sebagai sumber atas informasi yang terpercaya dalam perubahan dan perbandingan sumber ekonomi setelah terjadinya kegiatan usaha dari waktu ke waktu.

c. Pembacaan terhadap informasi keuangan sebagai perkiraan atas posisi perusahaan.

\subsection{Laporan Keuangan}

PSAK No. 1 tentang Penyajian Laporan Keuangan (revisi 2015) menyatakan pelaporan keuangan adalah suatu sajian yang tersusun atas posisi keuangan dan kinerja keuangan. Jadi laporan keuangan merupakan salah satu yang menjadi informasi yang sangat penting dalam menilai perkembangan perusahaan.

\subsubsection{Pengertian Laporan Keuangan}

Menurut Bambang Riyanto (2012:327), Laporan Finansiil(Financial Statement), yaitu memberikan ikhtisar atas keadaan suatu perusahaan, dimana Neraca yang mencerminkan nilai aktiva,utang, dan modal sendiri, dan laporan rugi dan laba mencerminkan atas hasil yang telah dicapai selama periode tertentu.

\subsubsection{Tujuan dan Manfaat Laporan Keuangan}

Laporan keuangan dapat diterapkan dengan tujuan yaitu sebagai penyedia atas informasi yang berhubungan dengan posisi,kinerja, dan perubahan posisi keuangan suatu perusahaan yang bermanfaat sebagai pengambilan keputusan ekonomi perusahaan.

\subsubsection{Sifat Laporan Keuangan}

Laporan keuangan disusun dengan maksud untuk mendapatkan gambaran atas kemajuan dari pelaporan keuangan secara periodic dalam perusahaan. Pencatatan atas yang telah dilakukan dalam penyusunan laporan keuangan diharuskan sesuai dengan prinsipprinsip akuntansi yang telah berlaku.Sifat Laporan Keuangan menurut Kasmir (2013 :12) adalah:

1. Bersifat historis

2. Bersifat menyeluruh

\subsection{Penyajian Laporan Keuangan}

Menurut PSAK 1 (2015 : 128 ) Pernyataan ini tentang mengatur persyaratan penyajian laporan keuangan, struktur laporan keuangan, dan persyaratan minimal atas isi 
laporan keuangan. Entitas menerapkan pernyataan ini didalam penyusunan dan penyajian laporan keuangan yang bertujuan untuk umum dengan SAK. Kompenen laporan keuangan lengkap terdiri dari :

a. Laporan atas posisi keuangan pada akhir periode;

b. Laporan atas laba rugi dan penghasilan komprehensif lain selama periode;

c. Laporan atas perubahan ekiutas selama periode;

d. Laporan atas arus kas selama periode;

e. Catatan atas laporan atas

\subsubsection{Jenis - jenis laporan keuangan}

Menurut Hery (2015), jenis laporan yaitu:

1. Neraca

Laporan yang menunjukkan informasi pada setiap kondisi ataupun posisi keuangan perusahaan pada tanggal tertentu. Dirumuskan oleh FASB dalam SFAC no. 6, Dalam kompenen naraca meliputi yaitu:
a. Aktiva
b. Kewajiban
c. Ekuitas

2. Laporan laba/rugi

Menurut James C. Van Horne dalam Kasmir (2013), laporan laba rugi adalah ringkasan atas pendapatan dan biaya perusahaan selama periode tertentu dan diakhiri dengan laba atau rugi pada periode tersebut.Laporan laba rugi ataupun perhitungan laba rugi dapat disajikan dalam dua bentuk, yaitu :

1. Bentuk Langsung (Single Step)

2. Bentuk Bertahap (Multiple Step)

\subsection{Analisis Laporan Keuangan}

Dalam mengukur kinerja atas keuangan, kondisi keuangan atas suatu perusahaan maka dapat dilakukan dengan menganalisis atau menganalisa laporan keuangan sehingga dapat memberikan pemahaman dan kekuatan kepada perusahaan.

\subsubsection{Pengertian Analisis Laporan Keuangan}

Menurut Hery (2015 : 132), analisis laporan keuangan merupakan suatu proses dalam membedakan laporan keuangan ke dalam unsurnya dan menelaah masing-masing dari unsur tersebut yaitu dengan suatu tujuan untuk memperoleh pemahaman yang baik dan tepat atas laporan keuangan itu sendiri.

\subsection{Kinerja Keuangan}

Menurut Wibowo ( $2014: 7$ ), "kinerja yaitu berasal dari pengertian performance. Adapun yang memberikan pengertian performance yaitu sebagai hasil kerja.

\subsection{Analisis Rasio Keuangan}

\subsubsection{Pengertian Analisis Rasio Keuangan}

Analisis rasio merupakan alat yang penting dalam menganalisis keuangan. Menganalisis rasio keuangan merupakan teknik dalam menganalisa laporan keuangan yang paling banyak diterapkan oleh perusahaan.

\subsubsection{Hubungan Kinerja Keuangan dan Rasio Keuangan}

Menurut Fahmi (2012 : 50) menyatakan bahwa rasio keuangan dan kinerja keuangan sangat berkaitan erat. Karena Rasio keuangan sangat banyak jumlahnya dan pada setiap rasio itu mempunyai kegunaanya masing-masing.

\subsubsection{Bentuk-Bentuk Rasio Keuangan}

Rasio keuangan berguna sebagai penentuan kesehatan keuangan suatu perusahaan baik pada masa saat sekarang ini maupun masa yang datang. Bentuk-bentuk atas rasio keuangan menurut Kasmir (2013) sebagai berikut:

1. Rasio Likuiditas (liquidity Ratio) 
2. Rasio Solvabilitas

3. Ratio Profitabilitas ( Probafitability Ratio)

\subsection{Rasio Keuangan Bank}

\subsubsection{Pengertian Rasio Keuangan}

Ukuran yang digunakan yaitu untuk mengetahui kesehatan dan mengetahui atas kondisi keuangan dilihat dari laporan keuangan yang disajikan oleh perusahaan secara periodic.

\subsubsection{Rasio Keuangan Menurut Bank Indonesia}

Peraturan Perundang-undang Bank Indonesia berdasarkan surat edaran Bank Indonesia No. 6/10/PBI/2004 tentang Sistem Penilaian Tingkat Kesehatan Bank Umum. Tingkat kesehatan bank adalah hasil penilaian kualitatif atas berbagai aspek yang berpengaruh terhadap kondisi atau kinerja suatu bank melalui penilaian kuantitatif dab atau penilaian kualitatif terhadap faktor-faktor permodalan, kualitas asset, manajemen, rentabilitas, likuiditas, dan sensivitas terhadap risiko pasar.

\subsubsection{Jenis-Jenis Rasio Keuangan Bank}

Menurut Kasmir (2013). Jenis rasio keuangan bank adalah :

1. Rasio Likuiditas Bank (Liquidity Ratio)

Rasio ini digunakan sebagai pengukur atas kemampuan perusahaan dalam memenuhi kewajiban financial jangka pendek.
a. Quick Ratio
b. Investing Policy Ratio
c. Cash Ratio
d. Loan to Deposit Ratio
e. Assets to Loan Ratio

2. Rasio Solvabilitas

Menunjukkan atas kekuatan bank dalam pengembalian terhadap utang jangka panjang.
a. Primary Ratio
b. Capital Ratio

3. Rasio Rentabilitas

Rasio ini dugunakan untuk mengukur tingkat efisiensi usaha dan profitabilitas yang di capai oleh bank.
a. Gross Profit Margin
b. Return On Equity
c. Return On Assets
d. Net Interest Margin
e. Beban Operasional Terhadap Pendapatan

\section{METODE PENELITIAN}

\subsection{Jenis dan sumber data}

Jenis penelitian yang akan diterapkan dalam pembahasan ini merupakan penelitian yang komparatif, yaitu dengan melakukan perbandingan kinerja Bank Perkreditan Raya (BPR) Dana Raya Manado dari periode tahun 2014 sampai tahun 2016 dengan menggunakan analisis terhadap rasio keuangan diantaranya rasio rentabilitas, likuiditas, dan solvabilitas. 


\subsection{Sampel dan teknik pengambilan sampel}

Menurut Kasmir (2013) analisis berdasarkan rasio- rasio keuangan bank, meliputi ;

1. Rasio Likuiditas

a. Quick Ratio

$$
\text { Quick Ratio }=\frac{\text { Cash Assets }}{\text { Total Deposit }} \quad \text { X } 100 \%
$$

b. Investing Policy Ratio

$$
\text { Investing policy ratio }=\frac{\text { Securities }}{\text { Total deposit }} \times 100 \%
$$

c. Cash Ratio

$$
\text { Cash Ratio }=\frac{\text { Short Term Borrowing }}{X 100 \%}
$$

d. Loan to Deposit Ratio

$$
\text { Loan to Deposit Ratio }=\frac{\text { Total Loan }}{\text { Total Deposit / equity }} \times 100 \%
$$

e. Assets to Loan Ratio

$$
\text { Assets to Loan Ratio }=\frac{\text { Total Loan }}{\text { Total Assets }} \times 100 \%
$$

2. Ratio Solvabilitas

a. Primary Ratio

$$
\text { Primary Ratio }=\quad \text { Equity Capital }
$$

b. Capital Ratio

$$
\text { Equity Capital }
$$

$$
\mathrm{CAR}=\frac{\text { Total Loans }+ \text { securities }}{\mathrm{X} 100 \%}
$$

3. Ratio Rentabilitas

a. Gross Profit Margin

$$
\text { Operating Income-Operating Expence }
$$

$$
\mathrm{GMP}=\frac{\mathrm{O}}{\text { Operating Income }} \times 100 \%
$$

b. Return Equity Capital

$$
\mathrm{ROE}=\frac{\text { Laba Setelah Pajak }}{\text { Rata-rata Equity }} \times 100 \%
$$

c. Return On Assets

$$
\text { Laba Sebelum Pajak }
$$

$$
\mathrm{ROA}=\frac{}{\text { Rata-rata Total Assets }} \times 100 \%
$$

d. Net Interest Margin

$$
\mathrm{NIM}=\frac{\text { Pendapatan Bunga Bersih }}{\text { Rata-rata Aktiva Produktif }} \times 100 \%
$$


e. Rate Return On Loans

$$
\text { Rate Return On Loans }=\frac{\text { Interest Income }}{\text { Total Loan }} \times 100 \%
$$

f. $\mathrm{BOPO}$

$$
\mathrm{BOPO}=\frac{\text { Total Beban Operasional }}{\text { Total Pendapatan Operasional }} \times 100 \%
$$

\section{3. $\quad$ Metode analisis}

Maka metode analisa data yang akan digunakan dalam penelitian adalah deskriptif kuantitatif yaitu analisis yang mendasarkan pada perhitungan untuk mengetahui tingkat dari likuiditas, dan profitabilitas dan sebagai dasar atas pengambilan keputusan. Data yaitu berupa laporan keuangan yang dianalisis dengan rasio keuangan sebagai dasarnya yang diperlukan untuk dapat memperoleh informasi untuk perkembangan perusahaan pada masa yang akan datang.

\section{HASIL ANALISIS DAN PEMBAHASAN}

\subsection{Hasil analisis}

Berdasarkan hasil penelitian, informasi mengenai tingkat likuiditas, solvabilitas, dan profitabilitas yang mempengaruhi posisi keuangan dan kinerja bank harus diukur untuk mengetahui sejauh apakah tingkat efisiensi keuangan bank. Karena itu perlu dilakukan analisis untuk keuangan bank sesuai informasi keuangan yang disajikan dalam laporan keuangan bank yang tersedia. Dengan penilaian terhadap laporan neraca dan rugi laba dapat diukur dengan rasio-rasio dalam laporan keuangan yang saling berhubungan. Dalam mengukur analisis rasio-rasio keuangan digunakan dua jenis laporan yang tersaji yaitu laporan keuangan neraca dan laba rugi.

Berikut ini disajikan analisis keuangan terhadap laporan keuangan Bank Perkreditan Rakyat Dana Raya Manado berdasarkan informasi laporan keuangan untuk mengukur efisiensi keuangan bank dengan menggunakan analisis dari rasio likuiditas, solvabilitas, dan profitabilitas, sebagai berikut :

a.Quick Ratio

Hasil perhitungan dari nilai Quick Ratio pada BPR Dana Raya Cabang Manado tahun 2014 dan 2015 mengalami penurunan. Dari prenstase 62,02\% pada tahun 2014 mengalami penurunan sekitar 2,48\% menjadi 59,54\% pada tahun 2015. Dikarenakan terjadi penurunan pada asett tunainya, kemudian pada tahun 2016 terjadi kenaikan pada deposito sebesar 4,6\% menjadi 60,00\%. Dengan nilai dari Quick Ratio dari tahun 2014 hingga 2016 BPR Dana Raya Manado masih mampu memenuhi kewajiban pada deposannya.

\section{b.Loan to Deposit Ratio}

Dari hasil perhitungan yang dapat di informasikan, nilai dari $L D R$ pada tahun 2014 dengan presentase 45,71\% mengalami kenaikan pada tahun 2015 dengan presentase 49,15\% .Disebabkan oleh meningkatnya jumlah kredit yang diberikan. Dan pada tahun 2016 kembali menurun pada presentase $45,61 \%$. Penurunan dari $L D R$ dikarenakan pertumbuhan dari pihak ketiga yang lebih besar dibanding dengan kredit yang diberikan. Maka rasio $L D R$ dari Bank Perkreditan Rakyat Dana Raya periode 2014 sampai 2016 belum memenuhi standart kriteria Bank Indonesia yaitu sebesar 100\%.

Perhitungan Tingkat Solvabilitas Bank a. Capital Adequacy Ratio

Dari hasil perhitungan yang di informasikan, dapat dilihat nilai dari $C A R$ pada Bank Perkreditan Rakyat Dana Raya Manado pada tahun 2014 dengan presentase 15,43\% dan 
kemudian meningkat pada tahun selanjutnya 2015 dengan presentase sebesar $18,46 \%$ dan kembali naik sedikit sekali dengan presentase 18,47\% pada tahun 2016. Disebabkan oleh ATMR kredit lebih besar yang tidak di imbangi dengan setoran permodalan pemegang saham. Nilai dari CAR pada yaitu bahwa modal Bank Perkreditan Rakyat Dana Raya belum mampu menutupi kegiatan perkeditan.

\section{KESIMPULAN DAN SARAN}

\subsection{Kesimpulan}

Berdasarkan penelitian yang dilaksanakan tepatnya pada Bank Perkreditan Rakyat Dana Raya Manado, maka penulis mengambil kesimpulan :

1. Penilaian terhadap Likuiditas berdasarkan pada data analisa dan perhitungan dari Quick Ratio, Cash Ratio, Loan to Deposit Ratio, dan Assets to Loan Ratio maka Bank Perkreditan Rakyat Dana Raya Manado masih mampu membayar kewajiban finansialnya melalui liquid assets yang dimiliki.

2. Penilaian atas Solvabilitas pada Bank Perkreditan Rakyat Dana Raya Manado dengan menggunakan rasio Primary Ratio dan Capital Ratio maka perusahaan masih memiliki permodalan yang memadai dalam membiayai kegiatannya.

3. Penilaian atas Rentabilitas dengan menganalisis rasio Gross Profit Margin, Return on Asset, Net Interest Margin, Return on Equity,dan BOPO maka dalam perhitungan yang didapat perusahaan masih mengalami fluktuasi, tetapi laba perusahaan masih tetap ada peningkatan.

\subsection{Saran}

1. Pada penilaian kinerja keuangan Bank Perkreditan Rakyat Dana Raya Manado masih mengalami fluktuasi, oleh sebab itu harus lebih diperhatikan agar tidak terjadi penurunan yang terlalu jauh yang dapat mengakibatkan perusahaan tidak sanggup menyelesaikan permasalahan keuangan.

2. Melakukan evaluasi secara terperinci terhadap kondisi keuangan Bank Perkreditan Rakyat Dana Raya Manado agar dapat memperbaiki dan menutupi kelemahan pada perusahaan.

\section{DAFTAR PUSTAKA}

Bambang Riyanto. 2012. Dasar-dasar Pembelanjaan. Edisi 4. Yogyakarta: BPFE

Bansal, Rohit 2014, 'A Comperative Analysis of the Financial Ratios of Selected Banks in the India for the period of 2011-2014', Finance and Accounting, Vol.5 No.19.

Bogale, Ermias 2017, 'Financial Performance Analysis of Privately Owned Commercial :Banks in Ethiopia', Finance and Accounting, Vol.8, No.3.

Erakipia, Apolonaris Felix. (2016). Analisis Laporan Keuangan Sebagai Dasar Penilaian Kinerja Keuangan Pada UMKM Amungme dan Kamoro. Skripsi (tidak dipublikasi). Fakultas Ekonomi dan Bisnis. Universitas Sam Ratulangi, Manado

Fahmi, I. 2012. Analisis Laporan Keuangan. Bandung: Alfabeta.

Hery, SE, M.Si, 2015. Analisis Laporan Keuangan: Pendekatan Rasio Keuangan. Yogyakarta: CAPS (Center for Academic Publishing Service)

Hilman, Rodif. (2014). Kinerja Keuangan Menggunakan Analisis Rasio Likuiditas, Leverage, Aktivitas, dan Profitabilitas Untuk Pengambilan keputusan Pada PT. PLN Area Manado. Skripsi (tidak dipublikasi). Fakultas Ekonomi dan Bisnis. Universitas Sam Ratulangi, Manado

Ikatan Akuntan Indonesia. 2015. Pernyataan Standar Akuntansi Keuangan 
Kajananthan, R 2014, 'Liquidity, Solvency and Profitability Analysis Using Cash Flow Ratio and Traditional Ratio : The Telecommunication Sector in Sri Langka', Finance and Accounting, Vol.5, No.23.

Kalele, Amelia E. (2015). Analisis Efisiensi Penggunaan Modal Kerja Perusahaan Dengan Rasio Keuangan; Studi Kasus Pada PT. Semen Baturaja, TBK. Skripsi. Fakultas Ekonomi dan Bisnis. Universitas Sam Ratulangi, Manado.

Kasmir S.E. M.M., 2013,Analisis Laporan Keuangan. Rajawali Pers : Jakarta

Kasmir. 2014. Dasar-dasar Perbankan Edisi Revisi 2014. Penerbit PT Raja Grafindo Persada, Jakarta

Lahonda, Finolitha Y. (2014). Analisis Kinerja Keuangan Pada PT. PLN (Persero) Wilayah Suluttenggo Area Manado. Skripsi (tidak dipublikasi). Fakultas Ekonomi dan Bisnis. Universitas Sam Ratulangi, Manado

Maith, Hendry Andres. (2013). Analisis Laporan Keuangan Dalam Mengukur Kinerja Keuangan Pada PT. Mandala Sampoerna, TBK. Skripsi (tidak dipublikasi). Fakultas Ekonomi dan Bisnis. Universitas Sam Ratulangi, Manado

Mamahit, Rollando M.F (2014). Analisis Perbandingan Kinerja Keuangan Bank Milik Pemerintah dengan Bank Milik Swasta Nasional di Indonesia. Skripsi. Fakultas Ekonomi dan Bisnis. Universitas Sam Ratulangi, Manado.

Manoppo, Junia Patriscia. 2012. Analisa Laporan Keuangan dalam Menilai Kinerja Keuangan Perusahaan pada PT. Bank Sulut Manado. Skripsi (tidak dipublikasi). Fakultas Ekonomi dan Bisnis. Universitas Sam Ratulangi, Manado.

Munadi, Meryho M. (2015). Analisis Perbandingan Kinerja Keuangan Pada Bank Rakyat Indonesia (Persero) Tbk dan Bank Mandiri (Persero) Tbk Periode 2012-2015. Skripsi (tidak dipublikasi). Fakultas Ekonomi dan Bisnis. Universitas Sam Ratulangi, Manado

Munawir, S. 2012. Analisis Informasi Keuangan, Liberty, Yogyakarta.

Nwaobia, Appolos N 2015, 'Financial Statements' Analysis and IFRS Adoption during the Transitioning Period: The Case of Nigerian Banks', Finance and Accounting, Vol.6, No.20.

Pangalila, Auddy T (2015). Analisis Perbandingan Kinerja Keuangan Bank Mandiri (Persero) Tbk, Bank Central Asia Bank (Persero) Tbk, dan Bank Cimb Niaga (Persero) Tbk. Skripsi. Fakultas Ekonomi dan Bisnis. Universitas Sam Ratulangi, Manado.

Pongoh, Marsel. (2013). Analisis Laporan Keuangan Untuk Menilai Kinerja Keuangan PT. Bumi Resources TBK. Skripsi (tidak dipublikasi). Fakultas Ekonomi dan Bisnis. Universitas Sam Ratulangi, Manado

Pura, Rahman. 2013 Pengantar Akuntansi 1 Pendekatan Siklus Akuntansi, Jakarta: Penerbit Erlangga.

Samhan, Dr Hussein Mohammad 2015, 'Determinants of Financial Performance of Jordan Islamic Bank', Finance and Accounting, Vol.6, No.8.

Subramanyam, K.R. (2014). Financial Statement Analysis. Eleventh Edition.

Tanor, Melisa Olivia. 2015. Analisis Laporan Keuangan Dalam Mengukur Keuangan Pada PT.Bank Artha Graha Internasional, TBK. Skripsi (tidak dipublikasi). Fakultas Ekonomi dan Bisnis. Universitas Sam Ratulangi, Manado

Thayib, Balgis. (2017). Analisis Perbandingan Kinerja Keuangan Bank Syariah dan Bank Konvensional. Skripsi (tidak dipublikasi). Fakultas Ekonomi dan Bisnis. Universitas Sam Ratulangi, Manado

Welson, Westwind (2015). Analisis Laporan Keuangan Sebagai Kriteria Pemberian Kredit Oleh PT.Bank Tabungan Negara (Persero) TBK. Skripsi (tidak dipublikasi). Fakultas Ekonomi dan Bisnis. Universitas Sam Ratulangi, Manado 
Wensen, Nindri. (2015). Analisis Perbandingan Kinerja Keuangan Bank Mandiri (Persero) Tbk dan Bank Central Asia (persero) Tbk Periode Tahun 2011-2015. Skripsi (tidak dipublikasi). Fakultas Ekonomi dan Bisnis. Universitas Sam Ratulangi, Manado.

Were, Ina Marica. (2017). Analisis Laporan Keuangan Perbankan Dalam Kaitan Pemberian Kredit Kepada Calon Nasabah (Studi Kasus Pada PT. Bank Papua Cabang Marauke Provinsi Papua). Skripsi. Fakultas Ekonomi dan Bisnis. Universitas Sam Ratulangi, Manado.

Wibowo, 2014. Manajemen Kinerja, Edisi keempat, Rajawali Pers, Jakarta.Yogyakarta. 